\title{
NIR Imaging of the Integrin-Rich Head and Neck Squamous Cell Carcinoma Using Ternary Copper Indium Selenide/Zinc Sulfide-Based Quantum Dots
}

\author{
Ilya Yakavets ${ }^{1}\left(\mathbb{D}\right.$, Aurelie Francois ${ }^{1}$, Maelle Guiot ${ }^{1}$, Nicolas Lequeux ${ }^{2}{ }^{\oplus}$, Alexandra Fragola ${ }^{2} \mathbb{D}$, \\ Thomas Pons ${ }^{2, *}$, Lina Bezdetnaya ${ }^{1, *}$ and Frédéric Marchal ${ }^{1,3}$ \\ 1 Research Department, Institut de Cancérologie de Lorraine, Université de Lorraine, CNRS UMR7039 CRAN, \\ 6 avenue de Bourgogne, 54519 Vandœuvre-lès-Nancy, France; i.yakavets@nancy.unicancer.fr (I.Y.); \\ a.francois@nancy.unicancer.fr (A.F.); maelle.guiot@outlook.fr (M.G.); f.marchal@nancy.unicancer.fr (F.M.) \\ 2 Laboratoire de Physique et d'Étude des matériaux (LPEM, UMR 8213), ESPCI Paris, PSL University, \\ CNRS, Sorbonne University, 10, rue Vauquelin, 75005 Paris, France; nicolas.lequeux@espci.fr (N.L.); \\ alexandra.fragola@espci.fr (A.F.) \\ 3 Surgical Department, Institut de Cancérologie de Lorraine, 6 avenue de Bourgogne, \\ 54519 Vandoeuvre-lès-Nancy, France \\ * Correspondence: thomas.pons@espci.fr (T.P.); 1.bolotine@nancy.unicancer.fr (L.B.); \\ Tel.: +33-(0)1-40-79-45-95 (T.P.); +33-(0)3-83-59-84-51 (L.B.)
}

Received: 2 November 2020; Accepted: 8 December 2020; Published: 11 December 2020

Simple Summary: Despite improved patient outcomes in a range of cancers, the prognostic of head and neck cancers remain poor, with more than 507,000 deaths annually. The management of these cancers requires multidisciplinary treatments, including radiotherapy, chemotherapy, or targeted molecular therapy; however, surgical resection is one of the first-line treatments for patients with head and neck cancers. In order to increase the positive surgical margin rate, we proposed a tumor-specific near-infrared nanoprobe for fluorescence-guided surgery. We confirmed the high specificity of the proposed nanoprobe towards head and neck cancer cells using advanced 3D stroma-rich spheroids.

\begin{abstract}
The efficient intraoperative identification of cancers requires the development of the bright, minimally-toxic, tumor-specific near-infrared (NIR) probes as contrast agents. Luminescent semiconductor quantum dots (QDs) offer several unique advantages for in vivo cellular imaging by providing bright and photostable fluorescent probes. Here, we present the synthesis of $\mathrm{ZnCuInSe/ZnS}$ core/shell QDs emitting in NIR ( 750 nm) conjugated to NAVPNLRGDLQVLAQKVART (A20FMDV2) peptide for targeting $\alpha_{v} \beta_{6}$ integrin-rich head and neck squamous cell carcinoma (HNSCC). Integrin $\alpha_{v} \beta_{6}$ is usually not detectable in nonpathological tissues, but is highly upregulated in HNSCC. QD-A20 showed $\alpha_{v} \beta_{6}$ integrin-specific binding in two-dimension (2D) monolayer and three-dimension (3D) spheroid in vitro HNSCC models. QD-A20 exhibit limited penetration (ca. $50 \mu \mathrm{m}$ ) in stroma-rich 3D spheroids. Finally, we demonstrated the potential of these QDs by time-gated fluorescence imaging of stroma-rich 3D spheroids placed onto mm-thick tissue slices to mimic imaging conditions in tissues. Overall, QD-A20 could be considered as highly promising nanoprobes for NIR bioimaging and imaging-guided surgery.
\end{abstract}

Keywords: indium-based quantum dots; near-infrared imaging; bioconjugates; integrins; multicellular tumor spheroids; time-gated fluorescence microscopy

\section{Introduction}

Worldwide, head and neck squamous cell carcinoma (HNSCC) accounts for more than 890,000 cases and more than 507,000 deaths annually [1]. The upfront surgery, as one of the first-line treatments 
for patients with HNSCCs along with radiotherapy or concurrent chemoradiation, requires accurate detection of tumor margins for positive postoperative prognosis. Among the important strategies for the detection of true positive margins is the evaluation of frozen sections during operation. However, this procedure is time and cost consuming and can be inaccurate [2]. In order to increase the positive surgical margins rate, the near-infrared (NIR) fluorescence-guided surgery (FGS) technique was proposed [3-5]. However, the efficient intraoperative identification of HNSCC requires the bright tumor-specific NIR probes as contrast agents.

Semiconductor quantum dots (QDs) represent an interesting class of fluorescent nanoparticles with exciting optical features such as a narrow tunable emission spectrum, high brightness, and photostability [6]. In particular, $\mathrm{CuInS}_{2}-$ and $\mathrm{CuInSe}_{2}$-based QDs have recently emerged as a bright, less-toxic alternative to the first generation of NIR-emitting QDs based on cadmium, lead, or mercury chalcogenides [7-9]. Additionally, QDs possess a long fluorescence lifetime enabling efficient time-gated imaging to detect fluorescence photons from QDs and rejecting photons from tissue autofluorescence [10]. As a result, the application of time-gated imaging considerably enhances the sensitivity of the detection of QD-labeled tissues in vivo [11].

Over recent decades, integrins received major attention as biological targets for cancer therapy [12]. Integrins represent a family of surface receptors that facilitate cell-cell and cell-extracellular matrix (ECM) interactions [13]. It is acknowledged that the integrin $\alpha_{v} \beta_{6}$ plays a role in promoting a number of different pathologies, including cancer and fibrosis [14,15]. Compared to widely-used integrin $\alpha_{v} \beta_{3}$, integrin $\alpha_{v} \beta_{6}$ is usually not detectable in nonpathological tissues, and is highly upregulated in various types of cancers, including HNSCC [16-18]. Given this strong specificity of $\alpha_{v} \beta_{6}$ integrin expression [16], we considered $\alpha_{v} \beta_{6}$ integrin as a highly tissue-specific target for NIR imaging of HNSCC $[17,19,20]$.

In the present study, we reported the synthesis, characterization and targeting ability of NIR-emitting QDs coupled with $\alpha_{v} \beta_{6}$ integrin-specific peptide for noninvasive imaging of HNSCC. We have prepared NIR-emitting ZnCuInSe/ZnS core/shell QDs using a high-temperature synthesis in an organic solvent and coated with a poly(sulfobetaine-block-imidazole) block polymer (Figure 1). In previous studies, we have shown that the first imidazole block ensures a strong anchoring to the QD surface (Figure 1, in orange) thanks to its multidentate nature [21]. The second block is composed of sulfobetaine (SPP) moieties, which virtually eliminates any nonspecific interactions between the QD and proteins or other plasma components [22]. To enable conjugation with an azide terminated NAVPNLRGDLQVLAQKVART (A20FMDV2) peptide, sulfobetaine copolymer ligands were modified with dibenzocyclooctyne. A20FMDV2 peptide is able to recognize $\alpha_{v} \beta_{6}$ integrin [23-25]. While A20FMDV2 peptide has been used for PET imaging $[23,26]$, its application for fluorescence imaging (i.e., conjugated with IRDye800 fluorescent dye) was reported only recently [27]. To assess the targeting ability of synthesized QDs to $\alpha_{v} \beta_{6}$ integrin-expressing cell lines, we tested QDs in stroma-rich co-culture HNSCC tumor spheroids, which recapitulate cell-ECM interactions. We tested the imaging capacity of these novel nanoprobes in tissue-like conditions using an advanced time-gated fluorescence imaging technique.

\section{Results}

\subsection{Synthesis and Characterization of $Q D s$}

NIR-emitting ZnCuInSe/ZnS core/shell QDs coated with 100\% SPP polymers were used as control samples. The functionalization of the QDs with a targeting peptide was performed by introducing a small $(<15 \%)$ proportion of DBCO (in green in Figure 1), a stretched activated alkyne which reacts with $\mathrm{N}_{3}$ azide groups from the peptide in copper-free conditions. Here, the peptide chosen for QD targeting is derived from the A20FMDV2 (NAVPNLRGDLQVLAQKVART) sequence from the foot-and-mouth disease virus [24]. As observed in structure-function analysis studies [24], the N-terminus of this peptide is not involved in the integrin recognition, so we used it to conjugate a $\mathrm{N}_{3}$ group and a 
(GGGS $)_{2}$ flexible linker to avoid steric hindrance issues from the SPP polymer. Colorimetric assays using $\mathrm{N}_{3}$-chromophores indicate that the efficiency of the conjugation of the $\mathrm{N}_{3}-\mathrm{A} 20$ peptide to the accessible reactive moieties on the nanocrystal surface is $>90 \%$, and that each QD is conjugated to ca. 7 peptides (Figure S1).

(a)

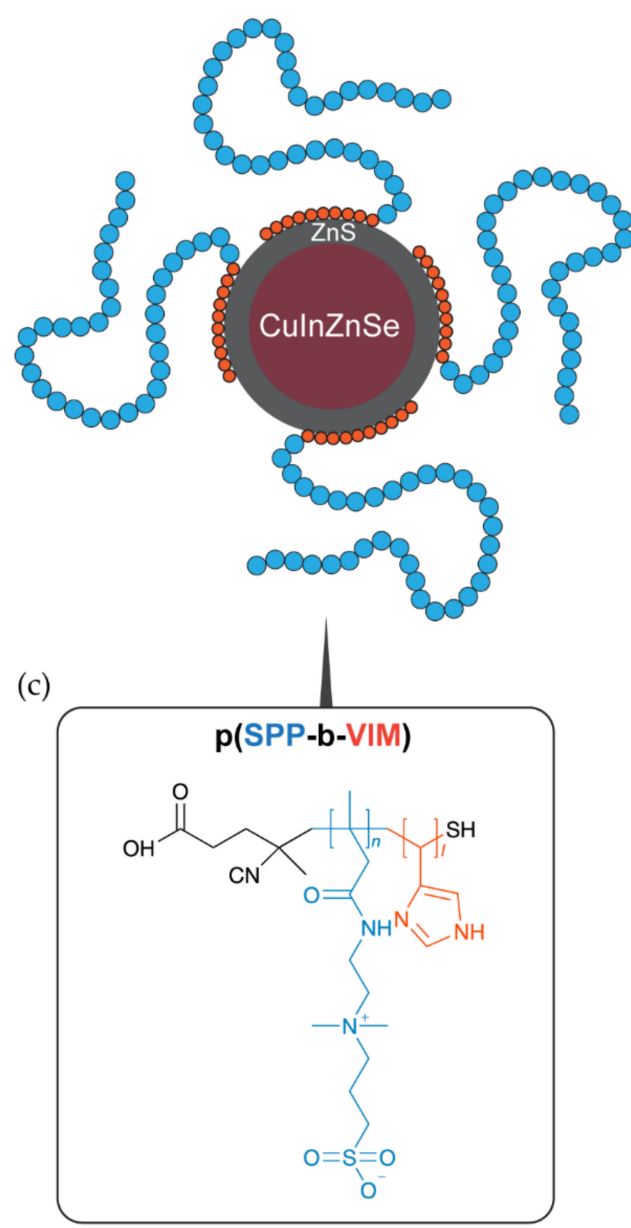

(b)
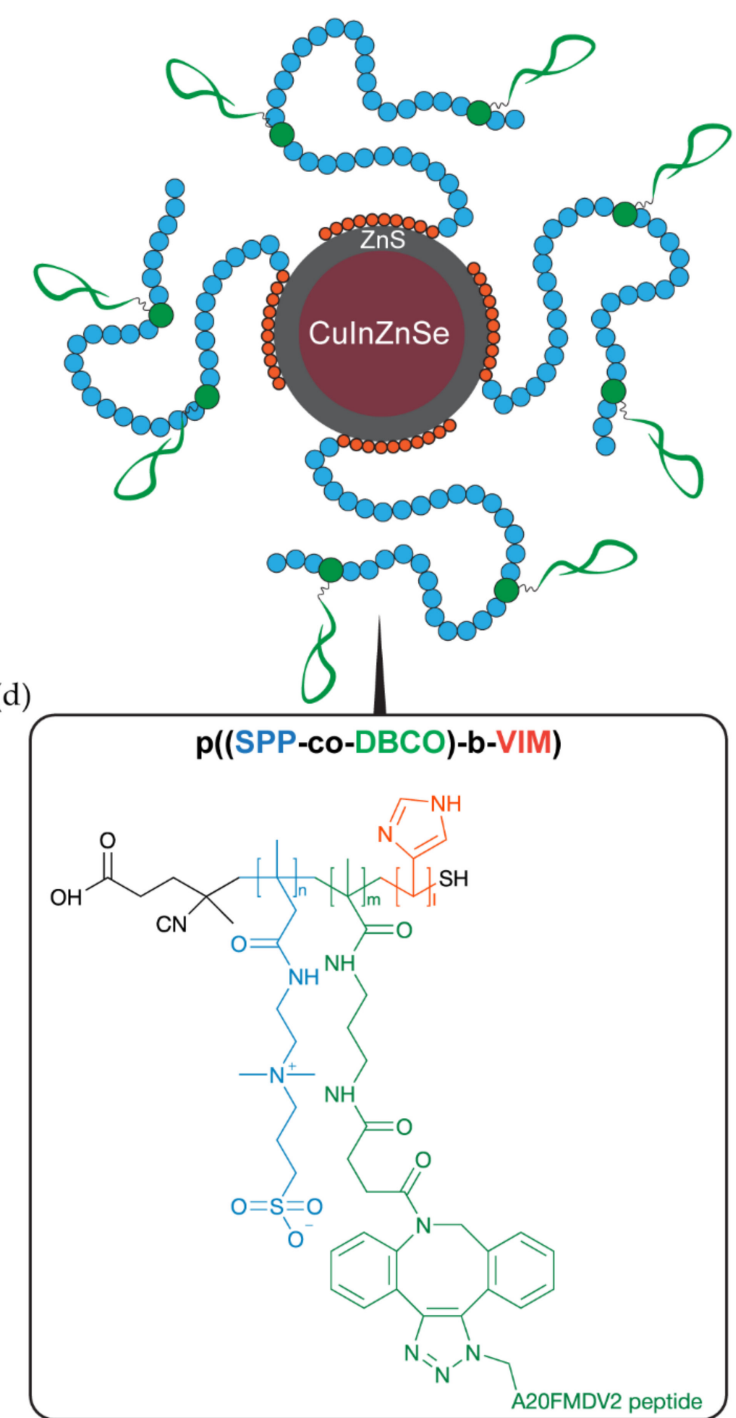

Figure 1. Schematics of $\mathrm{ZnCuInSe/ZnS} \mathrm{quantum} \mathrm{dot} \mathrm{(QD)} \mathrm{structure:} \mathrm{(a)} \mathrm{Control} \mathrm{QDs} \mathrm{(QD-SPP)} \mathrm{and}$ (b) targeted QD-A20. (c,d) Schematics of the QD-A20 surface chemistry. Control QDs (QD-SPP) were coated with pure (c) p(SPP-b-VIM) block polymers, while (d) the p((SPP-co-APMA)-b-VIM) polymeric ligand was reacted with DBCO-NHS and with the $\alpha_{v} \beta_{6}$-targeting peptide $\mathrm{N}_{3}$-A20 in QD-A20. The indicated degree of polymerization: sulfobetaine (SPP, blue, solubilization and antifouling, $\mathrm{n} \approx 35$ ), $\mathrm{DBCO}$ (green, functionalization, $\mathrm{m} \approx 5$ ) and imidazole (orange, anchoring, $1 \approx 10$ ).

The total hydrodynamic radius, including the polymer coating and hydration layers, was $13 \mathrm{~nm}$ (Figure 2a), as measured by dynamic light scattering (DLS), while the semiconductor core of QDs had a diameter of $\sim 3-4 \mathrm{~nm}$, according to the transmission electron microscopy measurements reported earlier $[11,28]$. During the synthesis of CuInSe cores, we incorporated zinc to increase the fluorescence quantum yield of QDs while keeping their emission wavelength in the NIR range [10,29]. QDs exhibit broad absorption and excitation spectra that extends from the UV to the NIR (ca. 350-800 nm) (Figure $2 \mathrm{~b}$ and Figure S2). In fact, QDs intensively emit fluorescence (quantum yield $=18 \%$ ) within 
the range of 650-800 $\mathrm{nm}$ (Figure 2c). Moreover, the synthesized QDs were characterized by a long component in the fluorescence decay of approximately $250 \mathrm{~ns}$ (Figure $2 \mathrm{~d}$ and Figure S3), enabling the use of time-gated detection to reduce the autofluorescence background and increase imaging sensitivity $[10,11]$. Concerning the stability of QDs, we previously reported their excellent stability for several months in physiological buffer under the storage at $4{ }^{\circ} \mathrm{C}$ and in plasma at $37^{\circ} \mathrm{C}$ [22].

(a)

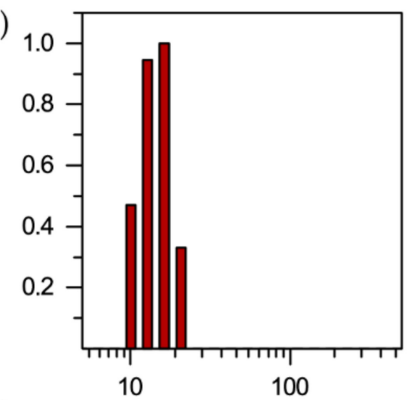

(b)

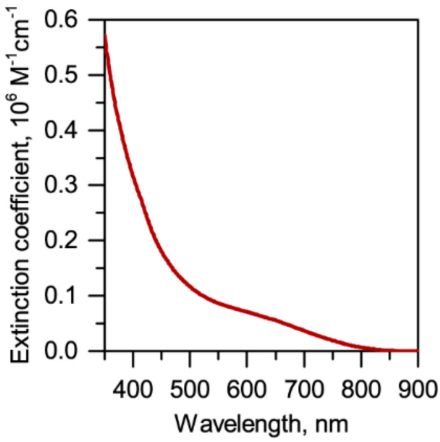

\begin{tabular}{lc}
\hline Characteristic & Value \\
\hline Radius $(\mathrm{r})$ & $13 \mathrm{~nm}$ \\
Extinction coefficient $(\varepsilon 450)$ & $0.18 \times 10^{6} \mathrm{M}^{-1} \mathrm{~cm}^{-1}$ \\
Emission wavelength $\left(\lambda_{\max }\right)$ & $739 \mathrm{~nm}$ \\
Fluorescence quantum yield $(\varphi)$ & $0.18 \pm 0.02$ \\
Fluorescence life-time $(\tau)$ & $(60 \pm 1) \mathrm{ns}(28 \%)$ \\
& $(246 \pm 2) \mathrm{ns}(72 \%)$ \\
\hline
\end{tabular}

(c)

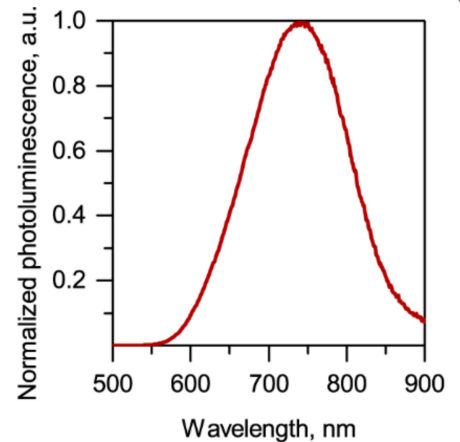

(d)

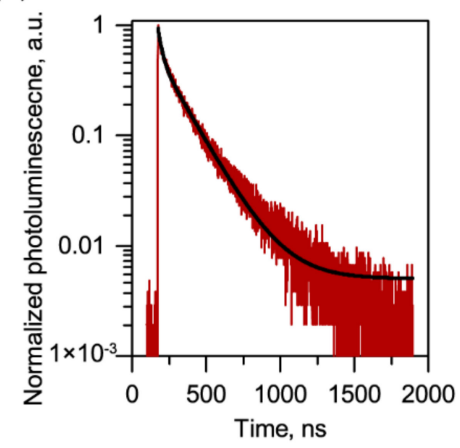

Figure 2. Characterization of QDs. (a) Dynamic light scattering (DLS) size distribution histograms and photophysical properties of QDs (right panel). (b) Absorbance and (c) fluorescence spectra of QDs. (d) Fluorescence emission decay curves of QDs. The black line corresponds to a biexponential fit, with the characteristic decay times and weights indicated in the right panel.

\subsection{Probing of NIR QDs as Optical Imaging Agents in $2 D$ and $3 D$ Models of HNSCC}

\subsubsection{Expression of $\alpha_{v} \beta_{6}$ Integrin}

The level of $\alpha_{v} \beta_{6}$ integrin expression in $\mathrm{FaDu}$ and MeWo monolayer cells was examined by Western blot analysis (Figure 3a). As follows from Figure 3a, the expression of $\beta_{6}$ subunit (band at $120 \mathrm{kDa}$ ) in 2D monolayer was much stronger in FaDu cells compared to MeWo (the ratio FaDu/MeWo was $2.6 \pm 0.9$, $p=0.0194 ; \mathrm{n}=5$, the one-sample t-test $(\mu=1))$. Moreover, we assessed the expression of $\alpha_{v} \beta_{6}$ integrin in 3D spheroids by immunofluorescent staining of cryosections (Figure 3b). Here, we used advanced stroma-rich 3D spheroid of HNSCC consisting of FaDu tumor cells and MeWo cancer-associated fibroblasts (CAFs), which were recently characterized in detail [30]. Using the liquid overlay technique, monoculture (F5) spheroids were generated from $5000 \mathrm{FaDu}$ cells, while the co-culture (F5M5) spheroids consisted of $5000 \mathrm{FaDu}$ cells and $5000 \mathrm{MeWo}$ cells. As seen from the images, $\alpha_{v} \beta_{6}$ integrins are strongly expressed in FaDu cells in both monoculture (F5) and co-culture (F5M5) spheroids (Figure 3b, in red). In co-culture F5M5 spheroids, we observed the areas with lower fluorescence intensity, corresponding to MeWo clusters (Figure 3b, in green). MeWo cells were pre-stained with PKH67 membrane dye in order to distinguish CAFs in the co-culture spheroids.

\subsubsection{Uptake of QDs in 2D Monolayer Cells}

First of all, we assessed the cytotoxicity of QDs on 2D monolayer FaDu and MeWo cells by MTT assay. The metabolic activity of cells was not affected after $24 \mathrm{~h}$ of incubation with $100 \mathrm{nM}$ of QDs 
( $p>0.3$, using the one-sample t-test with $\mu=1$ ). In fact, the viability of FaDu cells was $87 \pm 15 \%$ and $91 \pm 13 \%$ after incubation with QD-A20 and QD-SPP, respectively. In the case of MeWo cells, we observed $103 \pm 7 \%$ (QD-A20) and $89 \pm 23 \%$ (QD-SPP) of viable MeWo cells. It is worth noting that In-based QDs are considered as a less-toxic alternative to the first generation of NIR-emitting QDs.

(a)
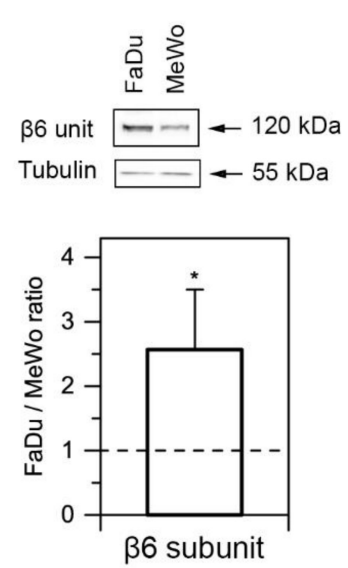

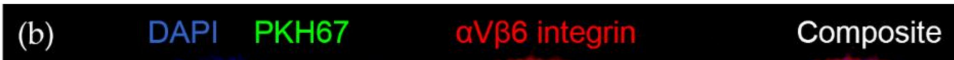

Figure 3. Expression of integrins in FaDu and MeWo cells. (a) Western blot of $\beta_{6}$ subunit expression in $\mathrm{FaDu}$ and MeWo cells and its quantification analysis. Data represent averages $\pm \mathrm{SD}\left(\mathrm{n}=5 ;{ }^{*} p<0.05\right.$, using the one-sample t-test $(\mu=1))$. (b,c) Typical fluorescence microscopy images of (b) F5 and (c) F5M5 spheroids cryosections, stained with antibody against $\alpha_{v} \beta_{6}$ integrins and DAPI. MeWo cells were pre-stained with PKH67 green membrane dye. Scale bar-100 $\mu \mathrm{m}$.

For uptake measurements, 2D monolayer cells were exposed to QD-A20 and QD-SPP for $3 \mathrm{~h}$ and analyzed by flow cytometry (Figure 4). As anticipated, the QD-A20 efficiently targeted both FaDu (Figure 4a) and MeWo (Figure 4b) cells due to the presence of $\alpha_{v} \beta_{6}$ integrins on their surface, compared to non-targeted QD-SPP, which tend to bind non-specifically to cell membranes $(p<0.001$, using ANOVA) (Figure 4c). Moreover, the mean fluorescence intensity (MFI) of FaDu cells exposed to QD-A20 was significantly higher ( $p<0.01$, using a two-sample t-test) than that of MeWo cells. It is worth noting that all cells in 2D monolayer culture are equally available for QDs. Thus, the number of labeled cells tends to $100 \%$ (single-peak distribution histograms in panels A and B, Figure 4).

\subsubsection{Uptake of QDs in 3D Spheroids}

There is growing evidence that 3D in vitro cell cultures better mimic the heterogeneity of in vivo tumors [31,32]. With this purpose, we tested the developed QDs in various concentrations in the F5 monoculture and F5M5 co-culture HNSCC spheroids. Compared to 2D monolayer cells, QD-A20 labeled only a limited fraction of cells in spheroids (Figure 5a). The detailed analysis demonstrated the saturation of the cellular uptake of QD-A20 in FaDu cells of F5 spheroids exposed up to $50 \mathrm{nM}$ of QDs (Figure 5b). Moreover, a similar saturation effect was also observed for the percentage of labeled FaDu cells of 3D spheroids (Figure 5c). We also confirmed the dose-independent uptake of QD-A20 in co-culture FaDu/MeWo (F5M5) spheroids (Figure 5d,e). MeWo cells were priory stained with PKH67 membrane dye, thus displaying increased autofluorescence compared with 2D monolayer culture (Figure 5e). We showed that $50 \mathrm{nM}$, as well as $100 \mathrm{nM}$ of QD-A20, labeled up to $25 \%$ of cells in spheroids, whereas QD-SPP—only up to $3(50 \mathrm{nM})$ and 5\% (100 nM). The thresholds of "labeled" cells were manually set to cover not more than $1 \%$ of cells in autofluorescnece (no drug) sample. The thresholds were calibrated separately for FaDu and MeWo cells in each independent experiment. Furthermore, 
QD-A20 preferably labeled FaDu cells in F5M5 spheroids for all QD concentrations (Figure 5g). At $50 \mathrm{nM}, \mathrm{QD}-\mathrm{A} 20$ were detected in $32 \%$ of FaDu cells and in $8 \%$ of MeWo cells. As seen in Figure $5 \mathrm{~g}, \mathrm{~h}$, in co-culture spheroids QD-A20 labeled preferably FaDu, but not MeWo. Figure 5i displayed that FaDu cells better accumulate QD-A20 than MeWo cells irrespective of QD-A20 concentration. Of note, at 5 -day post-seeding F5M5 spheroids consist of $65 \%$ of FaDu and $35 \%$ MeWo cells (Figure S4). Overall, the total fraction of QD-A20 labeled cells $(100 \mathrm{nM})$ was similar in F5 and F5M5 spheroids $(23.7 \pm 5.7 \%$ vs. $21.8 \pm 6.1 \%, p>0.05$; using the two-sample t-test). Importantly, no significant difference $(p>0.05$; using ANOVA) was observed between autofluorescence and QD-SPP fluorescence for all types of spheroids (Figure 5a). Finally, to compare the specificity of QD-A20 to FaDu and MeWo cells in F5M5 spheroids, we subtracted the autofluorescence of FaDu and MeWo cells (Figure S5). Thus, we confirmed a higher specificity of QD-A20 to FaDu tumor cells than that to MeWo (CAFs) in 3D co-culture F5M5 spheroids $(p<0.05$, using ANOVA).
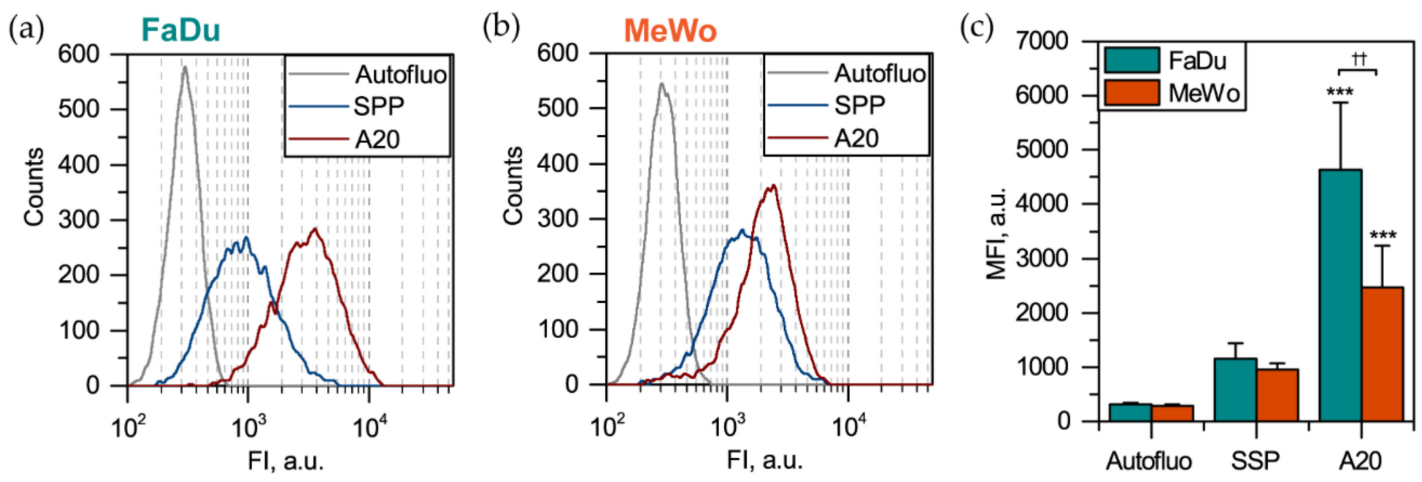

Figure 4. Uptake of QDs in 2D monolayer FaDu and MeWo cells. Typical cytometry distribution histograms of (a) FaDu and (b) MeWo monolayer cells 3 h post-incubation with $50 \mathrm{nM}$ of QDs. (c) Mean fluorescence intensity (MFI) of FaDu (cyan bars) and MeWo (orange bars) cells $3 \mathrm{~h}$ post-incubation with QDs ( $\mathrm{n}=6-7 ;{ }^{* * *} p<0.001$ compared to autofluorescence, using ANOVA; ${ }^{++} p<0.01$, using two-sample t-test).

\subsubsection{Penetration of QD-A20 in 3D Spheroids}

The flow cytometry analysis of dissociated spheroid does not allow the cells near the center to be distinguished directly from the cells on the periphery of spheroids. Thus, the penetration of QDs in $\mathrm{FaDu} / \mathrm{MeWo}$ spheroids was visualized by confocal laser scanning microscopy by excitation at $488 \mathrm{~nm}$ and registration at 730-800 nm. The Z-stacked confocal images from the spheroid surface to the center are shown in Figure 6a,b, providing better insight into the penetration of QDs in 3D spheroids. In our previous report, we demonstrated that five days post-seeding, the diameter of F5 and FM5 spheroids was $427 \pm 18 \mu \mathrm{m}$ and $478 \pm 22 \mu \mathrm{m}$, respectively [30]. According to the fluorescence confocal images, after $3 \mathrm{~h}$ of incubation, QD-A20 were accumulated by cells on the periphery of both types of spheroids. Thus, to quantify the detection depth $\left(\lambda_{\mathrm{ex}}=488 \mathrm{~nm}\right)$ of QDs in spheroids, we calculated the mean pixel intensity of the central part of each optical section (blue circle of 70 pixels in diameter) as a function of z-depth (Figure 6c,d). For F5 spheroids, the detection limit for QD-A20 was $74 \mu \mathrm{m}$ from the periphery for $488 \mathrm{~nm}$ excitation wavelength ( $p<0.05$; using ANOVA) (Figure $6 \mathrm{c}$ ). Of note, the observed signal for spheroids exposed to QD-SPP was similar to the autofluorescence of cells for all z-stack optical sections ( $p>0.05$; using ANOVA). In the case of F5M5 spheroids, we detected QD-A20 up to $56 \mu \mathrm{m}$ from the periphery ( $p<0.05$; using ANOVA) (Figure $6 \mathrm{~d}$ ). Given the limited fraction of labeled cells detected by flow cytometry and peripherical QD distribution observed by fluorescence microscopy, it seems unlikely that cells in the center of spheroids accumulate a detectable amount of QDs. 


\section{Monoculture F5 spheroids}

(a)

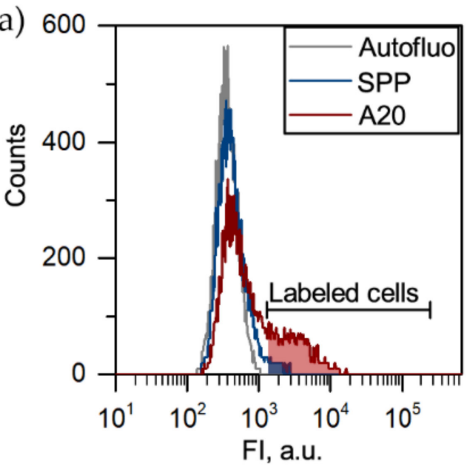

(b)

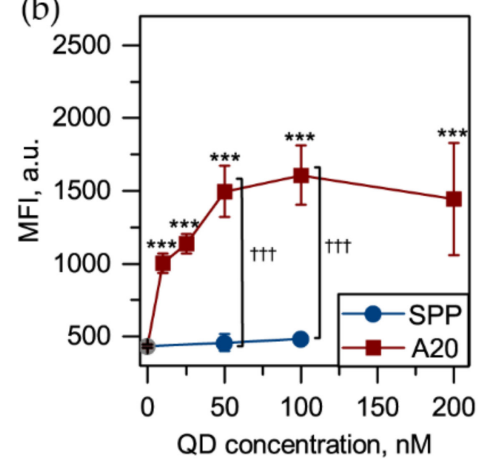

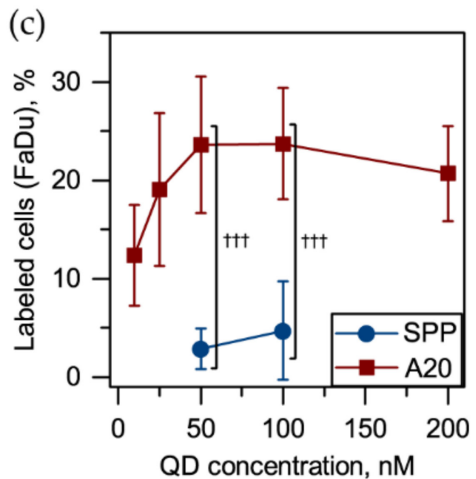

(f)
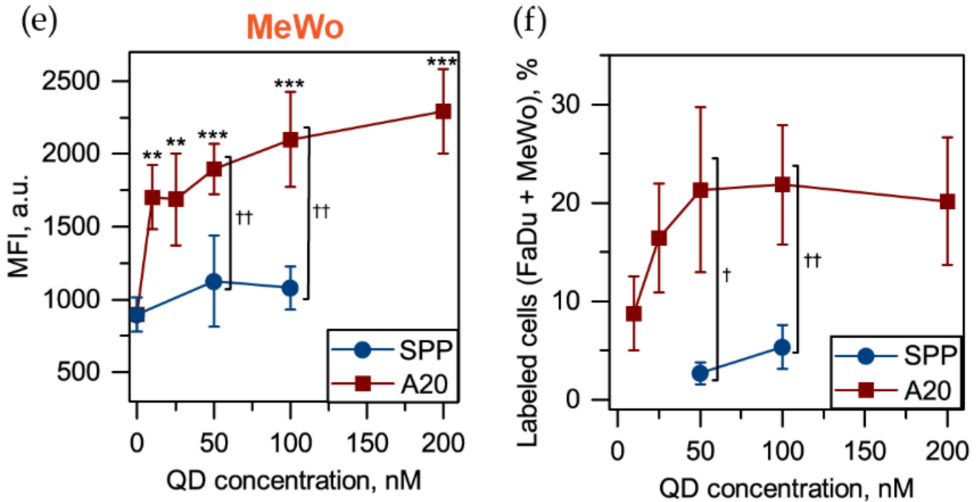

(g)
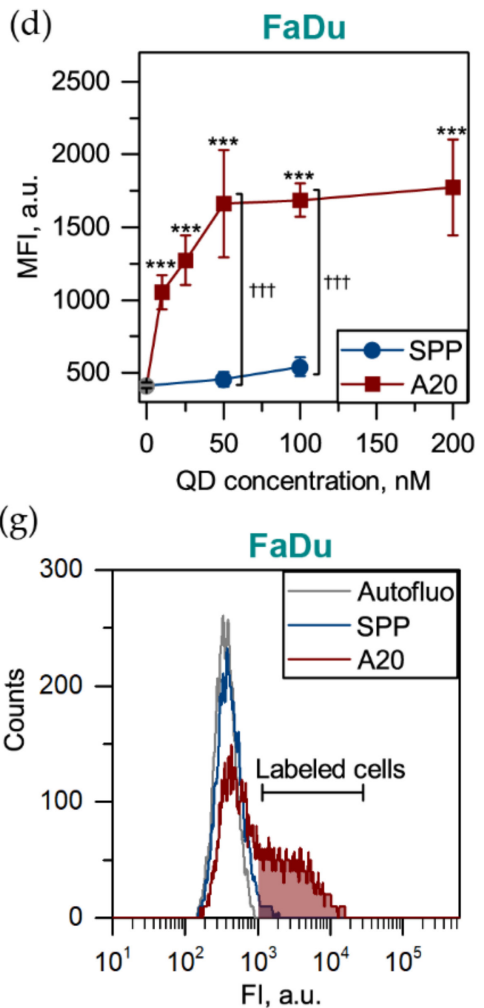

(h)

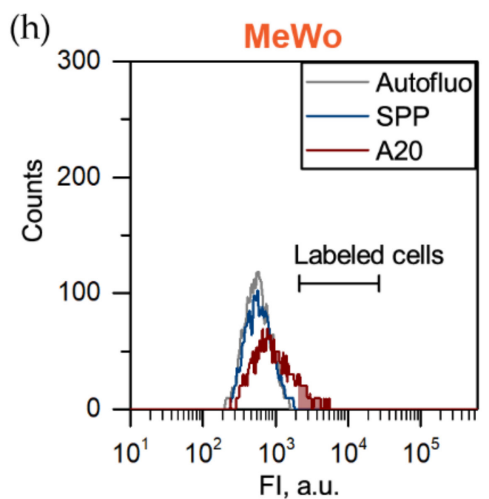

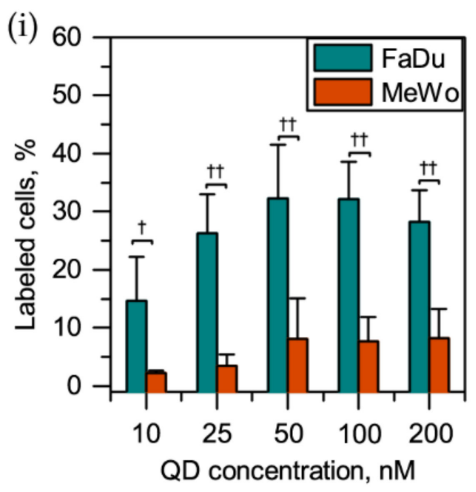

Figure 5. Uptake of QDs in 3D spheroids. (a) Flow cytometry histograms of cells from monoculture (F5) spheroids exposed for $3 \mathrm{~h}$ to $50 \mathrm{nM}$ QD-SPP (blue) and A20-QDs (red). (b) The MFI and (c) the number of labeled FaDu cells in F5 spheroids exposed to various concentrations of QD-SPP (blue) and QD-A20 (red). MFI of (d) FaDu; (e) MeWo cells and (f) total number of labeled cells in F5M5 spheroids in the function of QD concentration. Typical flow cytometry histograms of (g) FaDu and (h) MeWo cells from F5M5 spheroids exposed for $3 \mathrm{~h}$ to $50 \mathrm{nM}$ QD-SPP (blue) and A20-QDs (red). (i) The fraction of $\mathrm{FaDu}$ (cyan) and MeWo (orange) cells from F5M5 spheroids in the function of QD concentration. Data represent mean $\pm \mathrm{SD}(\mathrm{n}=4-7 ; * * *<0.01 ; * * * p<0.001$ compared to autofluorescence, using ANOVA; ${ }^{\dagger} p<0.05,{ }^{+\dagger} p<0.01$ and ${ }^{+t+} p<0.001$, using two-sample t-test). 


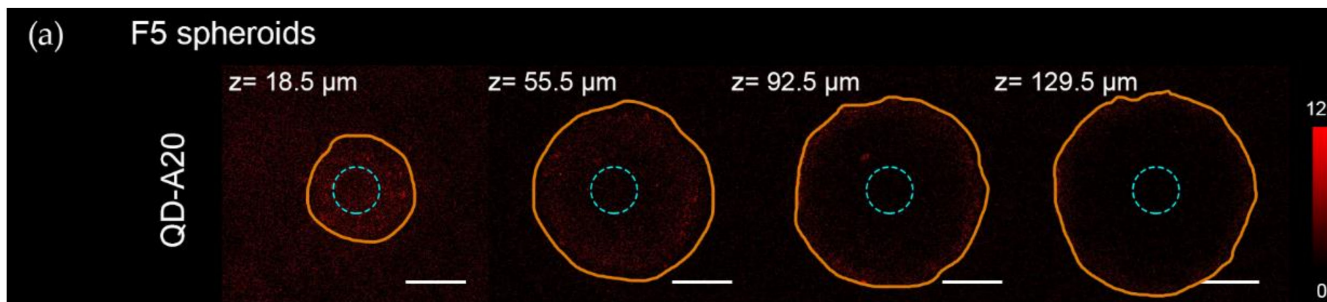

(b) F5M5 spheroids $z=18.5 \mu \mathrm{m}$

$$
\mathrm{z}=55.5 \mu \mathrm{m}
$$

$z=92.5 \mu \mathrm{m}$ $\mathbf{z}=129.5 \mu \mathrm{m}$
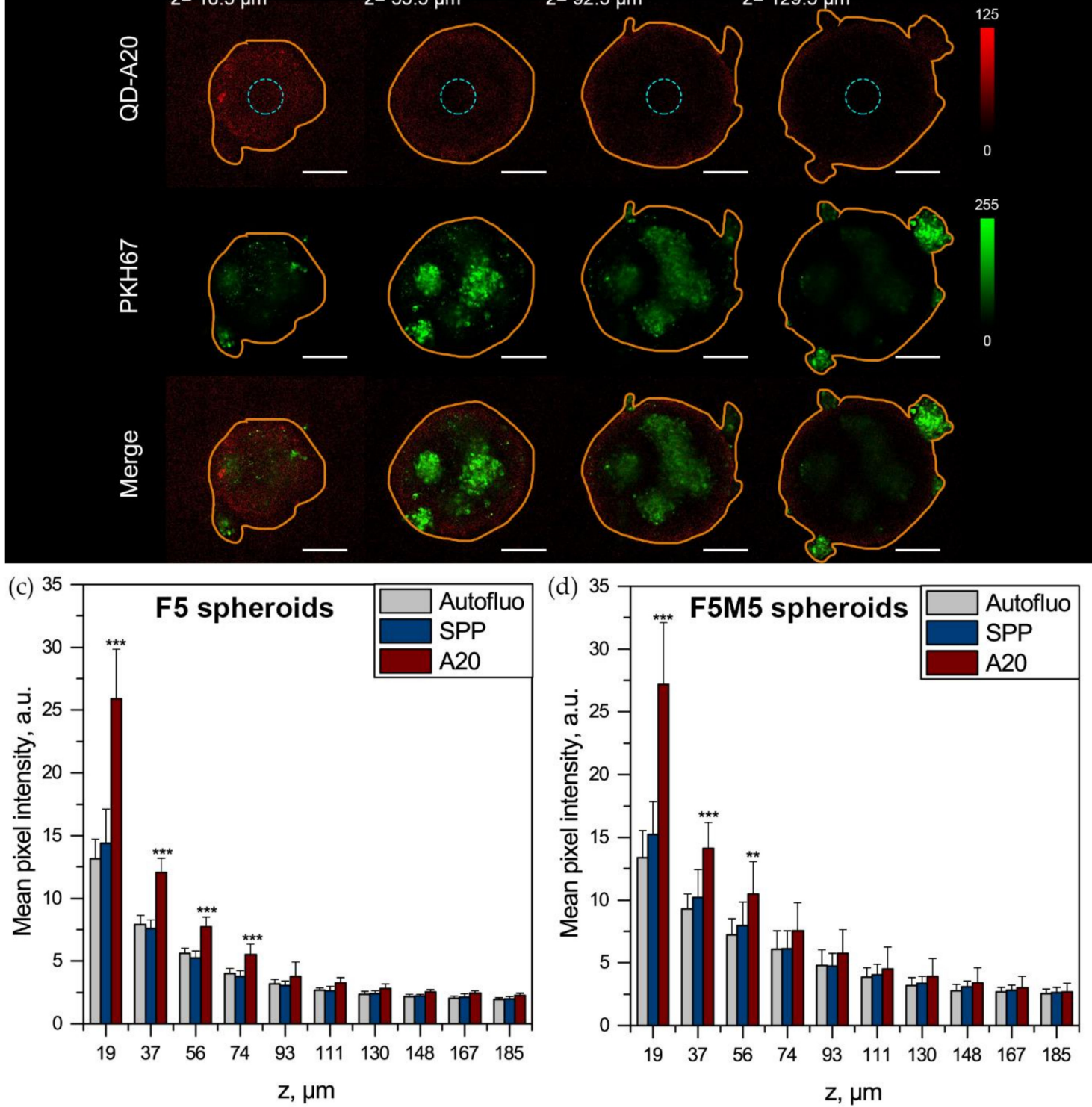

Figure 6. 3D Fluorescence imaging of QD-loaded head and neck squamous cell carcinoma (HNSCC) spheroids. 3D confocal microscopy of QD-A20 (red color, $\lambda_{\mathrm{em}}=730-800 \mathrm{~nm}$ ) distribution in different optical sections of (a) F5 and (b) F5M5 spheroids, incubated for $3 \mathrm{~h}$ with $50 \mathrm{nM}$ of QDs. MeWo cells were pre-stained with PKH67 membrane dye (green color, $\lambda_{\mathrm{em}}=530-600 \mathrm{~nm}$ ). The orange line displays the contour of spheroid. The mean pixel intensity of the central region (blue circles) of (c) F5 and (d) F5M5 spheroids $3 \mathrm{~h}$ post-incubation with $50 \mathrm{nM}$ of QDs as a function of the depth (z) of optical section. Scale bar $=100 \mu \mathrm{m}$. Data represent mean $\pm \mathrm{SD}\left(\mathrm{n}=3-7 ;{ }^{* *} p<0.01 ;{ }^{* *} p<0.001\right.$ compared to autofluorescence, using ANOVA). 


\subsubsection{Time-Gated Fluorescence Imaging of 3D Spheroids in Tissue-Like Conditions}

While in vitro fluorescence cell detection is very sensitive, the detection of very small tumor nodules in vivo is much more challenging due to the strong autofluorescence of tissues, providing a high non-uniform background. Long lifetime fluorescent QDs, coupled with time-gated imaging, afford a possibility for deep imaging. Introducing a controllable delay between the excitation pulse and the detection window (Figure $7 \mathrm{a}$ ) enables efficient rejection of fast $(\approx \mathrm{ns})$ autofluorescence photons and detection of slower $(\approx 100-300 \mathrm{~ns})$ QD fluorescence. As a proof of principle, we deposited F5M5 spheroids labeled with A20-QD onto mm-thick tissue slices to mimic tissue-like conditions. Figure $7 \mathrm{~b}$ shows that in the absence of time gating, the autofluorescence background prevents the identification of the tumor spheroid labeled with a small concentration of QDs (50 $\mathrm{nM})$. In contrast, when $\Delta t=40 \mathrm{~ns}$ delay is used between excitation and detection, the autofluorescence background is completely eliminated, revealing the presence of QD-labeled spheroid. For example, in the images shown in Figure 7, the signal-to-noise ratio (i.e., the ratio between signal-fluorescence intensity from the spheroid region after removal of average background-and noise-fluctuations of background autofluorescence) is 0.8 in the absence of time-gating, and around 20 with time-gating, thus improving sensitivity by a factor of 25 (Figure S6). Time-gated imaging requires a pulsed excitation source, in contrast to continuous sources used in other experiments. Our pulsed excitation source emits at $659 \mathrm{~nm}$, but any other wavelength would work as well, as long as it falls within the QD extinction spectrum. Overall, we can conclude that selective labeling of spheroid by QDs in tissue-like conditions can make QDs a suitable tool for targeted intraoperative imaging of $\alpha_{v} \beta_{6}$ integrin-rich HNSCCs.

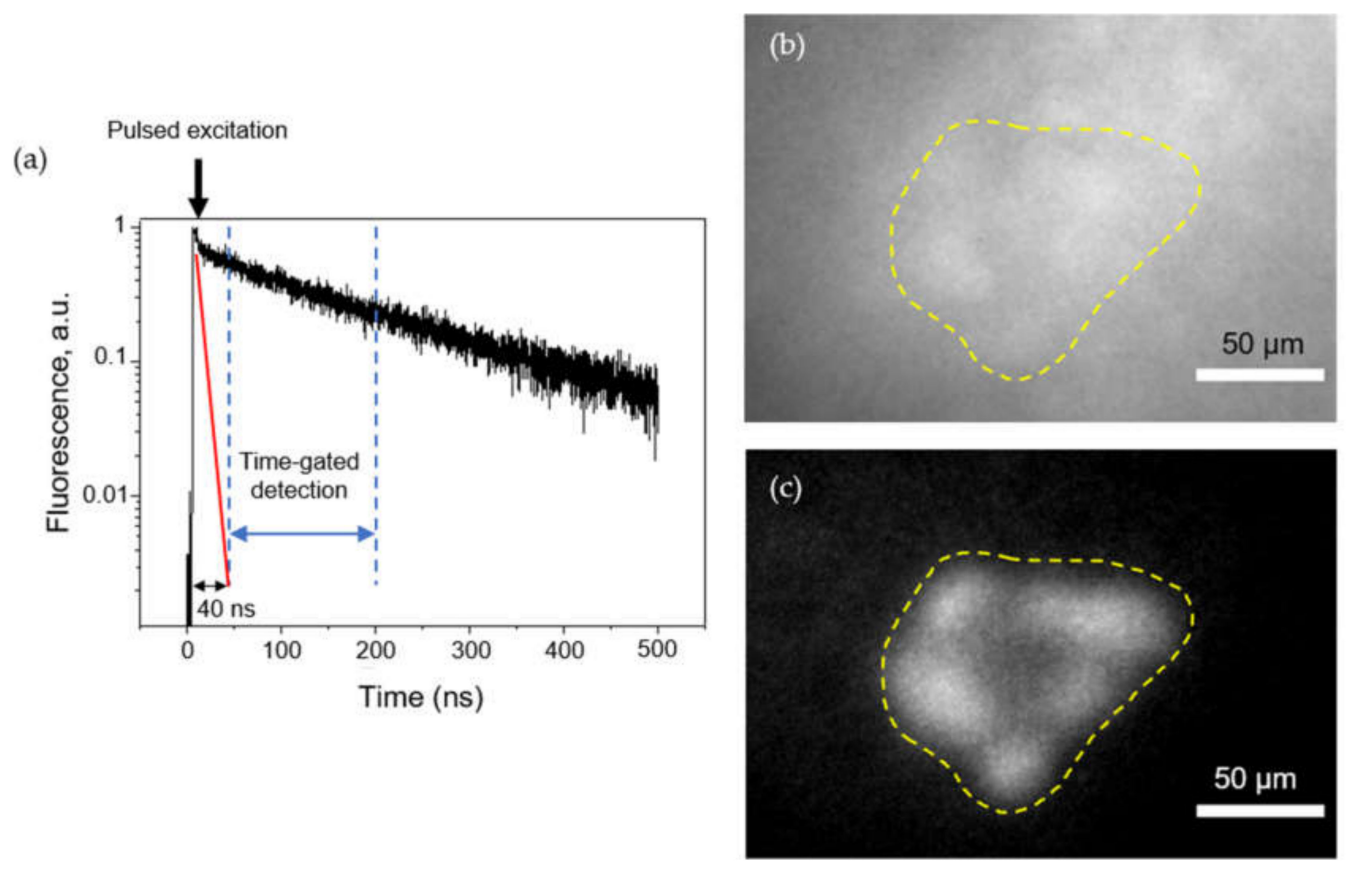

Figure 7. Time-gated imaging of QD-loaded co-culture HNSCC spheroids. (a) Autofluorescence (red) and fluorescence of QD-loaded spheroids (black) as a function of gate delay $\Delta \mathrm{t}$ (gate duration: $160 \mathrm{~ns}$ ). The first dotted line corresponds to the $40 \mathrm{~ns}$ delay selected for the following experiments. Typical fluorescence images at (b) delay $=0$ and (c) 40 ns, showing QD-loaded F5M5 spheroids deposited on a slice of tissue (scale bar $=50 \mu \mathrm{m}$ ). The yellow dotted line displays the contour of F5M5 spheroid.

\section{Discussion}

In recent years, NIR-emitting QDs have emerged as a promising tool in analytical applications, especially for in vivo imaging and therapy [33-35]. Here, we report the development and validation of QD-A20 bioconjugates as nanoprobes for noninvasive NIR imaging of $\alpha_{v} \beta_{6}$ integrin-rich HNSCC. 
Experiments with 2D monolayer and 3D spheroid HNSCC cultures consisting of the tumor (FaDu) and CAF (MeWo) cells indicated that the QD-A20 nanoprobe is highly specific to $\alpha_{v} \beta_{6}$ integrin. Overall, QD-A20 demonstrated a higher selectivity for FaDu than that for MeWo cells. In fact, we also demonstrated a 2.5-fold overexpression of $\alpha_{v} \beta_{6}$ integrin in FaDu cancer cells compared to MeWo CAFs (Figure 3). The overexpression of $\alpha_{v} \beta_{6}$ in FaDu cells confirmed the previously published reports [36]. It is worth noting that A20FMDV2 peptide is highly specific only for $\alpha_{v} \beta_{6}$ but not for other RGD-recognizing integrins (e.g., $\alpha_{v} \beta_{3}$ and $\alpha_{v} \beta_{5}$ ) [23]. Accordingly, we conclude that targeted QDs-A20 are selective to the HNSCC cells overexpressing $\alpha_{v} \beta_{6}$ integrin.

In clinical situations, tumor cells are organized as complex 3D tissue and associated with other cell types such as CAFs or macrophages. However, in the design of tumor-targeted nanoprobes, most in vitro studies focus on the labeling of tumor cells in 2D cultures. Moreover, there is increasing evidence that stroma could act as a physical barrier for nanoprobes restricting their penetration into the tumor stroma [37]. It is, therefore, critically important to characterize the behavior of tumor-targeted nanoprobes in the stroma-rich 3D model, in particular the extent to which they can selectively bind tumor vs. stromal cells and their capacity to penetrate in 3D tumor tissues. Thus, we tested QD-A20 in the advanced stroma-rich 3D model of HNSCC. This model recapitulates various levels of stroma expression in the HNSCC, contributing to the study of specific interactions of photoactive probes with stroma-rich HNSCC tissue. Due to the high binding specificity of QD-A20, the optimal concentration for NIR imaging with QD-A20 nanoprobe was quite low, equivalent to $50 \mathrm{nM}$ of QDs. QD-A20 efficiently labeled about $25 \%$ of total cells in the outer layers of stroma-rich co-culture spheroids; most of them were FaDu cancer cells ( $89 \pm 7 \%$ of total labeled cells). The saturation of QD-A20 uptake in cells is the obvious consequence of active targeting of a limited number of ligands-e.g., $\alpha_{v} \beta_{6}$ integrins, expressed on the surface of the cells [38]. Given the minimal toxicity of ZnCuInSe/ZnS core/shell, along with surface coating with SPP and low optimal concentration, we anticipated that QD-A20 could be compatible with clinical application.

Our results suggest the presence of diffusion limitations for the transport of QDs into the inner spheroid region. The obtained results confirmed literature reports on the limited (up to $100 \mu \mathrm{m}$ ) penetration of QDs into the 3D tumor spheroids [39-41]. For instance, Jarockyte and co-workers used mathematical modeling of QD penetration in spheroids and suggested that active transport plays a major role in QD penetration, whereas the diffusion of QDs through the ECM has no significant impact [39]. According to our data, the presence of ECM slightly decreased the detection depth of QD-A20 in spheroids acting as a physical barrier, as was assumed in the literature [37]. Nevertheless, the intravenous injection of QDs will allow selective staining of perivascular regions of the tumor. In fact, HNSCC are highly vascularized on the borders with normal tissues; thus, we may suppose an efficient application of developed QDs for delimitation of tumor borders. Despite the observed limited penetration of QD-A20 in spheroids, we could clearly detect the labeled tumor spheroids in tissue-like conditions using time-gated fluorescence microscopy due to the long lifetime of QD fluorescence. Such conditions do not remove nonspecific labeling from surrounding tissues. However, as shown in our manuscript, it significantly improves the sensitivity of detection vs. autofluorescence. While nonspecific QD signal in surrounding tissues would have to be estimated in vivo, we note that the high contrast obtained between $\mathrm{FaDu}$ (positive) and MeWo (negative) cell lines is encouraging for future in vivo targeting experiments.

\section{Materials and Methods}

\subsection{Materials}

$\mathrm{N}_{3}$-GGGSGGGSVPNLRGDLQVLAQKVART ( $\mathrm{N}_{3}$-A20) peptide ( $>95 \%$ purity) was synthesized on the IBPS platform (Sorbonne University, Paris, France). Chemicals for the synthesis and functionalization of QDs were purchased from Sigma-Aldrich (Saint-Quentin Fallavier, France). 


\subsection{Synthesis of $Q D s$}

QDs were synthesized by solvothermal methods according to previously published protocols [11]. Briefly, $\mathrm{Zn}$-Cu-In-Se cores were synthesized by the reaction of zinc acetate, copper chloride, indium chloride and selenouera in octadecene (ODE) at $260^{\circ} \mathrm{C}$, then a $\mathrm{ZnS}$ shell was grown by injection of zinc oleate and zinc diethyldithiocarbamate at $190^{\circ} \mathrm{C}$ in ODE, as described previously [11]. To solubilize these QDs in water, 3-[3-methacrylamidopropyl-(dimethyl)-ammonio]propane-1-sulfonate (sulfobetaine, $\mathrm{SPP}$ ), aminopropylmethacrylamide (APMA) and 4-vinylimidazole (VIM) monomers were used to synthesize $\mathrm{p}$ (SPP-b-VIM) and $\mathrm{p}((\mathrm{SPP}-\mathrm{co}-\mathrm{APMA})-\mathrm{b}-\mathrm{VIM})$ block polymers by RAFT polymerization, as described earlier [21,28]. QDs were solubilized into water using mercaptopropionic acid, a short labile ligand, then exchanged in a second step with p(SPP-b-VIM) or p((SPP-co-APMA)-b-VIM) polymers. They were purified by ultracentrifugation in sucrose gradients and ultrafiltration [21]. Functionalization with the $\alpha_{v} \beta_{6}$-targeting peptide was typically performed as follows: 3 nmol of QDs capped with $\mathrm{p}$ ((SPP-co-APMA)-b-VIM) was re-suspended in $300 \mu \mathrm{L}$ HEPES/NaCl buffer $(10 \mathrm{mM}, \mathrm{pH}$ 7.5) and reacted with dibenzocyclooctyne-NHS ester (DBCO-NHS) $(1.5 \mu \mathrm{mol} ; 5 \mathrm{~g} / \mathrm{L}$ in DMSO) at room temperature for $2 \mathrm{~h}$. QDs were purified from excess DBCO-NHS by ultrafiltration (3 rounds, $100 \mathrm{kDa}$ cut-off, $14,000 \mathrm{~g}, 12 \mathrm{~min}$ ). They were then mixed with $300 \mathrm{nmol}$ of $\mathrm{N}_{3}-\mathrm{A} 20$ for $16 \mathrm{~h}$ at room temperature and purified by three rounds of ultrafiltration. The number of accessible $\mathrm{NH}_{2}$ and $\mathrm{DBCO}$ units per QD was evaluated by reacting the QDs at each step with Cy5-NHS and Cy5- $\mathrm{N}_{3}$ dyes, respectively, for $6 \mathrm{~h}$ at a 100:1 dye:QD ratio, purifying them with 3 rounds of ultrafiltration and measuring the dye:QD ratio by absorbance.

\subsection{Cell Lines}

The FaDu (human pharynx squamous cell carcinoma) cell line was purchased from ATCC (Cat. No: ATCC HTB-43). Cells were cultured in phenol red-free Roswell Park Memorial Institute 1640 medium (RPMI-1640, Invitrogen, Carlsbad, CA, USA), supplemented with $9 \%(\mathrm{vol} / \mathrm{vol})$ heat-inactivated fetal bovine serum (FBS, Sigma-Aldrich, Saint-Quentin Fallavier, France), penicillin (10,000 IU) streptomycin $(10,000 \mathrm{mg} / \mathrm{mL}$ ) and $1 \%(\mathrm{vol} / \mathrm{vol}) 0.2 \mathrm{M}$ glutamin (Invitrogen, Carlsbad, CA, USA). As CAFs, we used MeWo cells (ATCC HTB-65), granular fibroblasts derived from human melanoma [42], cultured in Minimal Essential Medium (MEM, Sigma-Aldrich, Saint-Quentin Fallavier, France), supplemented with $9 \%(\mathrm{vol} / \mathrm{vol})$ of FBS and $1 \%(\mathrm{vol} / \mathrm{vol}) 0.1 \mathrm{M}$ sodium pyruvate (Sigma-Aldrich, Saint-Quentin Fallavier, France). Monolayer cells were kept in a humidified incubator $\left(5 \% \mathrm{CO}_{2}\right)$ at $37^{\circ} \mathrm{C}$. To ensure exponential growth, cells were reseeded every week.

\subsection{Spheroids Formation}

Spheroids were generated from FaDu cells using the liquid overlay technique, as described previously [30]. Briefly, to form monoculture (F5) spheroids, $200 \mu \mathrm{L}$ of FaDu cells $\left(2.5 \times 10^{4} \mathrm{cells} / \mathrm{mL}\right)$ was added to each well of a 96-well plate previously coated with $1 \%$ agarose $(w / v$ in water) and cultured at $37^{\circ} \mathrm{C}, 5 \% \mathrm{CO}_{2}$.

Co-culture (F5M5) spheroids were formed by seeding FaDu cells (100 $\mu \mathrm{L}$ at $5 \times 10^{4}$ cells $\left./ \mathrm{mL}\right)$ simultaneously with $100 \mu \mathrm{L}$ of MeWo cells at $5 \times 10^{4}$ cells $/ \mathrm{mL}$. To distinguish cells of different types in co-culture spheroid, MeWo cells were pre-stained with a membrane green fluorescent cell marker PKH67 (Sigma-Aldrich, Saint-Quentin Fallavier, France) according to the manufacturer's recommendations, before seeding with FaDu cells.

At day 5 post-seeding, between 4 and 8 spheroids were used for each experimental condition. For immunohistochemistry analysis, spheroids were embedded into resin Shandon Cryomatrix (ThermoFisher, Waltham, MA, USA), frozen, cut and $10 \mu \mathrm{m}$ thick sections were further analyzed by fluorescence microscopy. We used the cryosections with the diameter of the spheroid section about $400-450 \mu \mathrm{m}$. 


\subsection{Fluorescence Staining}

For incubation of spheroids with QDs, $100 \mu \mathrm{L}$ of the complete medium in each well with spheroids was carefully replaced with $150 \mu \mathrm{L}$ of concentrated QD solution, prepared in FBS-free medium. Spheroids were kept in a humidified incubator $\left(5 \% \mathrm{CO}_{2}\right)$ in the dark at $37^{\circ} \mathrm{C}$. At appropriate incubation time, spheroids were analyzed by fluorescence microscopy or flow cytometry after dissociation.

\subsection{QDs Characterization}

Fluorescence spectra and time-resolved fluorescence decays were acquired with a F-900 spectrometer (Edinburgh Instruments Ltd., Livingston, UK) equipped with a TCSPC card. The fitting function contains a background component. The best fit was obtained using the procedure included in the F-900 software. Absorbance spectra were registered using a Shimadzu UV-1800 absorption spectrometer. Dynamic light scattering (DLS) was performed on a Malvern CGS-3 goniometer system equipped with a HeNe laser $(633 \mathrm{~nm})$ and an ALV/LSE-5003 correlator (ALV-Laser Vertriebsgesellschaft m-b.H., Hessen, Germany). DLS measurements were performed using 3 runs of $30 \mathrm{~s}$ at 5 different angles.

\subsection{Western Blot}

Adherent cells were scrapped with ice-cold RIPA buffer 1X (Merck Millipore) supplemented with $20 \mu \mathrm{M}$ anti-protease (Phenylmethanesulfonyl fluoride, PMSF, Sigma). Western blot analysis was performed with ninety microgram protein lysate from each cell line. Samples were loaded to $10 \%$ non-reducing SDS PAGE. After 90 min of blotting and saturation with $5 \% w / v$ solution of non-fat powdered milk in TBST for $1 \mathrm{~h}$, the $\beta_{6}$ subunit of integrin $\alpha_{v} \beta_{6}$ was visualized. PVDF membrane was probed overnight at $4{ }^{\circ} \mathrm{C}$ with a rabbit anti-integrin $\beta_{6}$ specific antibody (clone $442.5 \mathrm{C} 4$; Abbexa; 1:500), or anti-tubulin antibody and followed by detection with appropriate HRP-conjugated secondary antibody (1:2000; Cell Signaling). Immune complexes were then detected by the chemiluminescence method and visualized with a gel imager (Azure C600, Azure Biosystems, Dublin, CA, USA). To compare the relative expression of $\beta_{6}$ in FaDu vs. MeWo cells, the band density was quantified using the ImageJ (NIH, USA) software and normalized to that of the tubulin.

\subsection{Histology and Immunofluorescence Analysis}

Cryosections were fixed with buffered $4 \%$ formaldehyde in PBS supplemented with sucrose $2 \%$ $(w / v)$, rinsed two times with PBS, and permeabilized with $0.2 \%$ Triton X-100 for $5 \mathrm{~min}$. Then, the sections were blocked with bovine serum albumin $(3 \% w / v)$ in PBS for $1 \mathrm{~h}$ at room temperature. Slides were incubated with the primary antibody in the blocking solution overnight at $4{ }^{\circ} \mathrm{C}$ in a humidified chamber (dilution1:100). Antibody $\alpha_{v} \beta_{6}$ integrin was purchased by Biorbyt (Cambridge, UK). Samples were then extensively washed before indirect immunostaining with a secondary anti-rabbit antibody conjugated with Alexa 555 in PBS solution for $1 \mathrm{~h}$ at room temperature (dilution 1:200). After several washings, samples were mounted with a nuclear counterstaining solution with DAPI (Vectashield with DAPI, Vector laboratories, Burlingame, CA, USA) and then observed by fluorescence microscopy (AX-70 Provis, Olympus, Paris, France).

\subsection{Cell Viability}

The viability of cells exposed $24 \mathrm{~h}$ to $100 \mathrm{nM}$ of QD-SPP and QD-A20 was estimated by MTT test. After washing with serum-free RPMI, $50 \mu \mathrm{L}$ of MTT solution $(2.5 \mathrm{mg} / \mathrm{mL}$ in PBS) was added to $100 \mu \mathrm{L}$ of culture medium for $3 \mathrm{~h}$ at $37^{\circ} \mathrm{C}$. At the end of the incubation, the MTT was removed, and the crystals formed were dissolved with $50 \mu \mathrm{L}$ of DMSO before absorbance measurements at $550 \mathrm{~nm}$ by a Multiskan spectrophotometer (Ascent, Thermo Fisher Scientific, Waltham, MA, USA). 


\subsection{Flow Cytometry}

The cellular uptake of QDs in 2D monolayer cells and 3D spheroids was analyzed by flow cytometry. For this purpose, monolayer cells or spheroids were incubated with QDs for $3 \mathrm{~h}$. The concentration of QDs was $50 \mathrm{nM}$ for 2D monolayer studies. In the case of 3D spheroids, we incubated 10, 25, 50, 100, $200 \mathrm{nM}$ of QD-A20 or 50, $100 \mathrm{nM}$ of QD-SPP. Spheroids were further dissociated by their transfer into a 12-well plate, washed twice with PBS, and incubated with twice diluted trypsin-EDTA in PBS (Sigma-Aldrich, Saint-Quentin Fallavier, France). The plate was protected from light and placed on the rotatory shaker ( $60 \mathrm{rpm}$ ) for 20-25 min. To inhibit trypsinization, $3 \mathrm{~mL}$ of the complete culture medium was added to each sample. Finally, dissociated spheroids were re-suspended, centrifugated (1500 rpm, $5 \mathrm{~min}$ ), and the pellet was re-suspended in the fresh serum-free culture medium. Cell suspensions were further subjected to flow cytometry analysis.

Flow cytometry analysis was performed using Accuri C6 Plus (BD, Franklin Lakes, NJ, USA), equipped with a laser emitting at $488 \mathrm{~nm}$. The fluorescence of PKH67 was detected in the fluorescence channel FL1 with a $533 \pm 30 \mathrm{~nm}$ filter under the excitation at $488 \mathrm{~nm}$, while the detection of QD's fluorescence was performed in an FL4 channel with $780 \pm 60 \mathrm{~nm}$ filter $\left(\lambda_{\mathrm{ex}}=488 \mathrm{~nm}\right)$. Data analysis was carried out using Accuri C6 Plus software (BD, Franklin Lakes, NJ, USA).

\subsection{Laser Scanning Fluorescence Microscopy}

Spheroids were incubated for $3 \mathrm{~h}$ in the dark at $37^{\circ} \mathrm{C}$ with $50 \mu \mathrm{M}$ of QDs, individually placed into Lab-Tek II chamber Slide (Roskilde, Denmark) and observed with a confocal laser-scanning microscope (Leica SP8 X AOBS LCSM, Leica microsystem, Wetzlar, Germany), equipped with an argon laser $\left(\lambda_{\mathrm{ex}}=488 \mathrm{~nm}\right)$. Fluorescence images were recorded using an $\times 10$, NA 0.4 dry objective. The QD fluorescence was collected at 730-800 nm, while the fluorescence of PKH67 at 520-570 nm. Image processing was performed with Image (NIH, USA) software.

\subsection{Time-Gated Fluorescence Microscopy}

After 5 days of co-culturing, FaDu:MeWo spheroids were labeled with $50 \mathrm{nM}$ QDs for $2 \mathrm{~h}$, rinsed and deposited over a thick $(>1 \mathrm{~mm})$ slice of tissue to mimic in vivo imaging conditions. Time-gated imaging was performed using a $659 \mathrm{~nm}, 5 \mathrm{MHz}$, pulsed laser source, focused on the sample using a 20x, NA 0.7 water immersion objective. The fluorescence was collected through the same objective, separated by a dichroic and a long pass filter (715LP, Semrock). The image was acquired using a gated intensifier (Picostar HRI, LaVision) synchronized with the pulsed laser and a charged coupled device camera (Roper QuantEM 512C). Fluorescence images were acquired with a ca. $160 \mathrm{~ns}$ time gate with a tunable delay between the start of the time gate and the laser pulse. Full fluorescence images correspond to a situation where the laser pulse is included within the time gate and includes autofluorescence and QD signal. Time-gated fluorescence images were acquired with a ca. $40 \mathrm{~ns}$ time delay.

\subsection{Statistics}

The data from at least three independent experiments are presented as the mean \pm standard deviation (SD). The one-sample t-test was used for statistical analysis of integrins expression in $\mathrm{FaDu}$ and MeWo cells with $\mu=1$ as $\mathrm{H}_{0}$. The statistical analysis of the two groups was performed with an unpaired, two-tailed t-test. Analysis of Variance (ANOVA) followed by Tukey's multiple comparisons test was used for comparison of three or more groups. Data analysis was carried out with the Origin software (OriginLab Corporation, Northampton, MA, USA).

\section{Conclusions}

In this study, we report the development and validation of QD-A20 bioconjugates as nanoprobes for noninvasive NIR imaging of $\alpha_{v} \beta_{6}$ integrin-rich HNSCC. Experiments with 2D monolayer and 3D 
spheroid HNSCC cultures consisting of tumor $(\mathrm{FaDu})$ and CAF (MeWo) cells indicated that the QD-A20 nanoprobe is highly specific to $\alpha_{v} \beta_{6}$ integrin. QDs-A20 were also tested in the advanced stroma-rich 3D model of HNSCC. Due to the high binding specificity of QD-A20, the optimal concentration for NIR imaging with a QD-A20 nanoprobe was quite low, equivalent to $50 \mathrm{nM}$ of QD. Given the minimal-toxicity of $\mathrm{ZnCuInSe/ZnS} \mathrm{core/shell,} \mathrm{surface} \mathrm{coating} \mathrm{with} \mathrm{SPP} \mathrm{and} \mathrm{low} \mathrm{optimal} \mathrm{concentration,}$ we anticipated that QD-A20 could be relatively nontoxic for clinical use. At the same time, QD-A20 efficiently labeled about $25 \%$ of total cells in the outer layers of stroma-rich co-culture spheroids; most of these were FaDu cancer cells (up to $90 \%$ of total labeled cells). Despite the observed limited penetration of QD-A20 in spheroids, we could clearly detect the labeled tumor spheroids in conditions close to in vivo using time-gated fluorescence microscopy, essentially due to the long lifetime of QD fluorescence.

It should be mentioned that further extensive studies are needed to confirm the ability of QD-A20 to image HNSCC in vivo, including pharmacokinetic properties and specificity of nanoprobe. Overall, we conclude that QD-A20 is a highly promising nanoprobe with an architecture suitably designed to preserve NIR emission and to accomplish a cellular targeting towards $\alpha_{v} \beta_{6}$ integrin receptors, thus paving the way for its potential application for NIR bioimaging and imaging-guided surgery.

Supplementary Materials: The following are available online at http://www.mdpi.com/2072-6694/12/12/3727/s1, Figure S1: Colorimetric assay of the efficiency of the conjugation of the $\mathrm{N}_{3}-\mathrm{A} 20$ peptide to the accessible reactive moieties. Figure S2: Photoluminescence excitation spectrum from the NIR QDs (detection at $750 \mathrm{~nm}$ ). Figure S3: Fluorescence decay of QD before and after functionalization with DBCO and A20 peptides. Figure S4: Flow cytometry histograms of $\mathrm{FaDu}$ and MeWo cells from co-culture (F5M5) spheroids exposed for $3 \mathrm{~h}$ to $50 \mathrm{nM}$ A20-QDs. Figure S5: The adjusted MFI values (autofluorescnece subtracted) of FaDu and MeWo cells from co-culture (F5M5) spheroids exposed for $3 \mathrm{~h}$ to $50 \mathrm{nM}$ of SPP-QDs and A20-QDs. Figure S6: Quantitative analysis of fluorescence images captured with and without time-dated detection.

Author Contributions: Conceptualization, I.Y., N.L., T.P., L.B. and F.M.; methodology, I.Y., A.F. (Aurelie Francois), A.F. (Alexandra Fragola) and T.P.; investigation, I.Y., A.F. (Aurelie Francois), M.G. and T.P.; writing-original draft preparation, I.Y.; writing—review and editing, I.Y., A.F. (Aurelie Francois), N.L., A.F. (Alexandra Fragola), T.P., L.B. and F.M.; visualization, I.Y.; supervision, L.B., T.P. and F.M.; funding acquisition, L.B., F.M. and T.P. All authors have read and agreed to the published version of the manuscript.

Funding: This research was funded by Campus France, grant number 41145VE, and the French “Ligue Nationale Contre le Cancer (CCIR-GE)", the Institut de Cancérologie de Lorraine.

Acknowledgments: The authors are grateful to Dominique Dumas (UMS2008 IBSLor-CNRS-UL-INSERM Plateforme d'Imagerie et de Biophysique Cellulaire PTIBC-IBISA platform) for the acquisition of confocal images. The authors Dominique Marius Le Prince for the proof-reading of the manuscript.

Conflicts of Interest: The authors declare no conflict of interest.

\section{References}

1. Aupérin, A. Epidemiology of head and neck cancers: An update. Curr. Opin. Oncol. 2020, 32, $178-186$. [CrossRef] [PubMed]

2. Layfield, E.M.; Schmidt, R.L.; Esebua, M.; Layfield, L.J. Frozen Section Evaluation of Margin Status in Primary Squamous Cell Carcinomas of the Head and Neck: A Correlation Study of Frozen Section and Final Diagnoses. Head Neck Pathol. 2018, 12, 175-180. [CrossRef] [PubMed]

3. Yokoyama, J.; Fujimaki, M.; Ohba, S.; Anzai, T.; Yoshii, R.; Ito, S.; Kojima, M.; Ikeda, K. A feasibility study of NIR fluorescent image-guided surgery in head and neck cancer based on the assessment of optimum surgical time as revealed through dynamic imaging. OncoTargets Ther. 2013, 6, 325-330. [CrossRef] [PubMed]

4. Egloff-Juras, C.; Bezdetnaya, L.; Dolivet, G.; Lassalle, H.-P. NIR fluorescence-guided tumor surgery: New strategies for the use of indocyanine green. Int. J. Nanomed. 2019, 14, 7823-7838. [CrossRef]

5. Cortese, S.; Kerrien, E.; Yakavets, I.; Meilender, R.; Mastronicola, R.; Renard, S.; Leroux, A.; Bezdetnaya, L.; Dolivet, G. ICG-induced NIR fluorescence mapping in patients with head \& neck tumors after the previous radiotherapy. Photodiagn. Photodyn. Ther. 2020, 31, 101838. [CrossRef]

6. Mattoussi, H.; Palui, G.; Na, H.B. Luminescent quantum dots as platforms for probing in vitro and in vivo biological processes. Adv. Drug Deliv. Rev. 2012, 64, 138-166. [CrossRef] 
7. Li, L.; Daou, T.J.; Texier, I.; Kim Chi, T.T.; Liem, N.Q.; Reiss, P. Highly Luminescent CuInS2/ZnS Core/Shell Nanocrystals: Cadmium-Free Quantum Dots for In Vivo Imaging. Chem. Mater. 2009, 21, 2422-2429. [CrossRef]

8. Helle, M.; Cassette, E.; Bezdetnaya, L.; Pons, T.; Leroux, A.; Plénat, F.; Guillemin, F.; Dubertret, B.; Marchal, F. Visualisation of sentinel lymph node with indium-based near infrared emitting Quantum Dots in a murine metastatic breast cancer model. PLoS ONE 2012, 7, e44433. [CrossRef]

9. Pons, T.; Pic, E.; Lequeux, N.; Cassette, E.; Bezdetnaya, L.; Guillemin, F.; Marchal, F.; Dubertret, B. Cadmium-free CuInS2/ZnS quantum dots for sentinel lymph node imaging with reduced toxicity. ACS Nano 2010, 4, 2531-2538. [CrossRef]

10. Bouccara, S.; Fragola, A.; Giovanelli, E.; Sitbon, G.; Lequeux, N.; Pons, T.; Loriette, V. Time-gated cell imaging using long lifetime near-infrared-emitting quantum dots for autofluorescence rejection. J. Biomed. Opt. 2014, 19, 051208. [CrossRef]

11. Pons, T.; Bouccara, S.; Loriette, V.; Lequeux, N.; Pezet, S.; Fragola, A. In Vivo Imaging of Single Tumor Cells in Fast-Flowing Bloodstream Using Near-Infrared Quantum Dots and Time-Gated Imaging. ACS Nano 2019, 13, 3125-3131. [CrossRef]

12. Wu, P.-H.; Opadele, A.E.; Onodera, Y.; Nam, J.-M. Targeting Integrins in Cancer Nanomedicine: Applications in Cancer Diagnosis and Therapy. Cancers 2019, 11, 1783. [CrossRef]

13. Hynes, R.O. Integrins: Bidirectional, Allosteric Signaling Machines. Cell 2002, 110, 673-687. [CrossRef]

14. Bandyopadhyay, A.; Raghavan, S. Defining the Role of Integrin $\alpha v \beta 6$ in Cancer. Curr. Drug Targets 2009, 10, 645-652. [CrossRef] [PubMed]

15. Koivisto, L.; Bi, J.; Häkkinen, L.; Larjava, H. Integrin $\alpha v \beta 6$ : Structure, function and role in health and disease. Int. J. Biochem. Cell Biol. 2018, 99, 186-196. [CrossRef] [PubMed]

16. Hsiao, J.-R.; Chang, Y.; Chen, Y.-L.; Hsieh, S.-H.; Hsu, K.-F.; Wang, C.-F.; Tsai, S.-T.; Jin, Y.-T. Cyclic alphavbeta6-targeting peptide selected from biopanning with clinical potential for head and neck squamous cell carcinoma. Head Neck 2010, 32, 160-172. [CrossRef] [PubMed]

17. Thomas, G.J.; Nyström, M.L.; Marshall, J.F. $\alpha \mathrm{v} \beta 6$ integrin in wound healing and cancer of the oral cavity. J. Oral Pathol. Med. 2006, 35, 1-10. [CrossRef]

18. Breuss, J.M.; Gallo, J.; DeLisser, H.M.; Klimanskaya, I.V.; Folkesson, H.G.; Pittet, J.F.; Nishimura, S.L.; Aldape, K.; Landers, D.V.; Carpenter, W. Expression of the beta 6 integrin subunit in development, neoplasia and tissue repair suggests a role in epithelial remodeling. J. Cell Sci. 1995, 108, 2241-2251.

19. Regezi, J.A.; Ramos, D.M.; Pytela, R.; Dekker, N.P.; Jordan, R.C.K. Tenascin and beta 6 integrin are overexpressed in floor of mouth in situ carcinomas and invasive squamous cell carcinomas. Oral Oncol. 2002, 38, 332-336. [CrossRef]

20. Van Aarsen, L.A.K.; Leone, D.R.; Ho, S.; Dolinski, B.M.; McCoon, P.E.; LePage, D.J.; Kelly, R.; Heaney, G.; Rayhorn, P.; Reid, C.; et al. Antibody-mediated blockade of integrin alpha v beta 6 inhibits tumor progression in vivo by a transforming growth factor-beta-regulated mechanism. Cancer Res. 2008, 68, 561-570. [CrossRef]

21. Tasso, M.; Giovanelli, E.; Zala, D.; Bouccara, S.; Fragola, A.; Hanafi, M.; Lenkei, Z.; Pons, T.; Lequeux, N. Sulfobetaine-Vinylimidazole Block Copolymers: A Robust Quantum Dot Surface Chemistry Expanding Bioimaging's Horizons. ACS Nano 2015, 9, 11479-11489. [CrossRef] [PubMed]

22. Debayle, M.; Balloul, E.; Dembele, F.; Xu, X.; Hanafi, M.; Ribot, F.; Monzel, C.; Coppey, M.; Fragola, A.; Dahan, M.; et al. Zwitterionic polymer ligands: An ideal surface coating to totally suppress protein-nanoparticle corona formation? Biomaterials 2019, 219, 119357. [CrossRef] [PubMed]

23. Hausner, S.H.; DiCara, D.; Marik, J.; Marshall, J.F.; Sutcliffe, J.L. Use of a Peptide Derived from Foot-and-Mouth Disease Virus for the Noninvasive Imaging of Human Cancer: Generation and Evaluation of 4-[18F]Fluorobenzoyl A20FMDV2 for In vivo Imaging of Integrin $\alpha v \beta 6$ Expression with Positron Emission Tomography. Cancer Res. 2007, 67, 7833-7840. [CrossRef] [PubMed]

24. DiCara, D.; Rapisarda, C.; Sutcliffe, J.L.; Violette, S.M.; Weinreb, P.H.; Hart, I.R.; Howard, M.J.; Marshall, J.F. Structure-function analysis of Arg-Gly-Asp helix motifs in alpha v beta 6 integrin ligands. J. Biol. Chem. 2007, 282, 9657-9665. [CrossRef] [PubMed]

25. Liu, H.; Wu, Y.; Wang, F.; Liu, Z. Molecular imaging of integrin $\alpha v \beta 6$ expression in living subjects. Am. J. Nucl. Med. Mol. Imaging 2014, 4, 333-345. [PubMed] 
26. Hausner, S.H.; Bauer, N.; Hu, L.Y.; Knight, L.M.; Sutcliffe, J.L. The Effect of Bi-Terminal PEGylation of an Integrin $\alpha v \beta_{6}$-Targeted ${ }^{18} \mathrm{~F}$ Peptide on Pharmacokinetics and Tumor Uptake. J. Nucl. Med. Off. Publ. Soc. Nucl. Med. 2015, 56, 784-790. [CrossRef]

27. Ganguly, T.; Tang, S.Y.; Bauer, N.; Sutcliffe, J.L. Evaluation of Two Optical Probes for Imaging the Integrin avß6- In Vitro and In Vivo in Tumor-Bearing Mice. Mol. Imaging Biol. 2020, 22, 1170-1181. [CrossRef]

28. Trapiella-Alfonso, L.; Pons, T.; Lequeux, N.; Leleu, L.; Grimaldi, J.; Tasso, M.; Oujagir, E.; Seguin, J.; d'Orlyé, F.; Girard, C.; et al. Clickable-Zwitterionic Copolymer Capped-Quantum Dots for in Vivo Fluorescence Tumor Imaging. ACS Appl. Mater. Interfaces 2018, 10, 17107-17116. [CrossRef]

29. Cassette, E.; Pons, T.; Bouet, C.; Helle, M.; Bezdetnaya, L.; Marchal, F.; Dubertret, B. Synthesis and Characterization of Near-Infrared $\mathrm{Cu}-\mathrm{In}-\mathrm{Se} / \mathrm{ZnS}$ Core/Shell Quantum Dots for In vivo Imaging. Chem. Mater. 2010, 22, 6117-6124. [CrossRef]

30. Yakavets, I.; Jenard, S.; Francois, A.; Maklygina, Y.; Loschenov, V.; Lassalle, H.-P.; Dolivet, G.; Bezdetnaya, L. Stroma-Rich Co-Culture Multicellular Tumor Spheroids as a Tool for Photoactive Drugs Screening. J. Clin. Med. 2019, 8, 1686. [CrossRef]

31. Millard, M.; Yakavets, I.; Zorin, V.; Kulmukhamedova, A.; Marchal, S.; Bezdetnaya, L. Drug delivery to solid tumors: The predictive value of the multicellular tumor spheroid model for nanomedicine screening. Int. J. Nanomed. 2017, 12, 7993-8007. [CrossRef] [PubMed]

32. Nii, T.; Makino, K.; Tabata, Y. Three-Dimensional Culture System of Cancer Cells Combined with Biomaterials for Drug Screening. Cancers 2020, 12, 2754. [CrossRef] [PubMed]

33. Kim, S.; Lim, Y.T.; Soltesz, E.G.; De Grand, A.M.; Lee, J.; Nakayama, A.; Parker, J.A.; Mihaljevic, T.; Laurence, R.G.; Dor, D.M.; et al. Near-infrared fluorescent type II quantum dots for sentinel lymph node mapping. Nat. Biotechnol. 2004, 22, 93-97. [CrossRef] [PubMed]

34. Cassette, E.; Helle, M.; Bezdetnaya, L.; Marchal, F.; Dubertret, B.; Pons, T. Design of new quantum dot materials for deep tissue infrared imaging. Adv. Drug Deliv. Rev. 2013, 65, 719-731. [CrossRef]

35. Mangeolle, T.; Yakavets, I.; Marchal, S.; Debayle, M.; Pons, T.; Bezdetnaya, L.; Marchal, F. Fluorescent Nanoparticles for the Guided Surgery of Ovarian Peritoneal Carcinomatosis. Nanomaterials 2018, 8, 572. [CrossRef]

36. Colley, H.E.; Hearnden, V.; Jones, A.V.; Weinreb, P.H.; Violette, S.M.; Macneil, S.; Thornhill, M.H.; Murdoch, C. Development of tissue-engineered models of oral dysplasia and early invasive oral squamous cell carcinoma. Br. J. Cancer 2011, 105, 1582-1592. [CrossRef]

37. Engin, A.B.; Nikitovic, D.; Neagu, M.; Henrich-Noack, P.; Docea, A.O.; Shtilman, M.I.; Golokhvast, K.; Tsatsakis, A.M. Mechanistic understanding of nanoparticles' interactions with extracellular matrix: The cell and immune system. Part. Fibre Toxicol. 2017, 14. [CrossRef]

38. Choi, C.H.J.; Alabi, C.A.; Webster, P.; Davis, M.E. Mechanism of active targeting in solid tumors with transferrin-containing gold nanoparticles. Proc. Natl. Acad. Sci. USA 2010, 107, 1235-1240. [CrossRef]

39. Jarockyte, G.; Dapkute, D.; Karabanovas, V.; Daugmaudis, J.V.; Ivanauskas, F.; Rotomskis, R. 3D cellular spheroids as tools for understanding carboxylated quantum dot behavior in tumors. Biochim. Biophys. Acta BBA Gen. Subj. 2018, 1862, 914-923. [CrossRef]

40. Mangeolle, T.; Yakavets, I.; Lequeux, N.; Pons, T.; Bezdetnaya, L.; Marchal, F. The targeting ability of fluorescent quantum dots to the folate receptor rich tumors. Photodiagn. Photodyn. Ther. 2019, 26, 150-156. [CrossRef]

41. Ulusoy, M.; Lavrentieva, A.; Walter, J.-G.; Sambale, F.; Green, M.; Stahl, F.; Scheper, T. Evaluation of $\mathrm{CdTe} / \mathrm{CdS} / \mathrm{ZnS}$ core/shell/shell quantum dot toxicity on three-dimensional spheroid cultures. Toxicol. Res. 2016, 5, 126. [CrossRef] [PubMed]

42. Choromańska, A.; Saczko, J.; Kulbacka, J.; Kamińska, I.; Skołucka, N.; Majkowski, M. Comparison of the influence of photodynamic reaction on the Me45 and MEWO cell lines in vitro. Contemp. Oncol. 2012, 16, 240-243. [CrossRef] [PubMed]

Publisher's Note: MDPI stays neutral with regard to jurisdictional claims in published maps and institutional affiliations. 